\title{
HUBUNGAN KEPATUHAN KONSUMSI OBAT ANTIDIABETIK TERHADAP KADAR HBA1C PADA PASIEN DM TIPE 2 DI RUMAH SAKIT UMUM DAERAH PROVINSI NUSA TENGGARA BARAT TAHUN 2019
}

\author{
Lintang Usnaini*, Winangun $^{* *}$, Musyarrafah ${ }^{* * *}$, Halia Wanadiatri $^{* * * *}$ \\ FakultasKedokteranUniversitas Islam Al-Azhar \\ Jl. Unizar No. 20 TuridaMataram \\ Email: usnainilintang@yahoo.com
}

\begin{abstract}
ABSTRAK
Prevalensi Diabetes Melitus (DM) di Nusa Tenggara Barat (NTB) berdasarkan Riset Kesehatan Dasar Provinsi NTB Tahun 2018, mengalami peningkatan dari tahun sebelumnya. Tingginya angka kejadian DM tipe 2 salah satunya disebabkan oleh pengendalian penyakit DM yang masih kurang baik. Faktor yang berperan dalam kegagalan pengontrolan glukosa darah pasien DM tipe 2 diantaranya disebabkan oleh ketidakpatuhan pasien terhadap pengobatan termasuk mengonsumsi obat antidiabetik. Kondisi ini dapat diketahui dengan adanya fluktuasi nilai dari kadar $\mathrm{HbAlc}$ pasien DM sehingga memberikan gambaran konsentrasi glukosa darah pasien DM rata-rata selama 2-3 bulan terakhir. Tujuan penelitian adalah mengetahui hubungan kepatuhan konsumsi obat antidiabetik dengan kadar HbA1c pada pasien DM tipe 2 di Rumah Sakit Umum Daerah (RSUD) Provinsi NTB Tahun 2019. Penelitian ini merupakan penelitian analitik observasional dengan desain cross sectional. Teknik pengambilan sampel menggunakan purposive sampling. Subjek penelitian terdiri dari 83 orang pasien DM tipe 2 yang diwawancara menggunakan kuesioner MMAS-8 untuk menilai tingkat kepatuhan responden dalam mengonsumsi obat antidiabetik dan kadar $\mathrm{HbA1c}$ diperoleh dari rekam medik. Data dianalisis menggunakan uji Chi Square dengan nilai signifikasi (p) adalah $\mathrm{p} \leq 0.05$. Hasil penelitian diperoleh nilai signifikansi (p) 0.000 yang menunjukkan adanya hubungan bermakna antara kepatuhan mengonsumsi obat antidiabetik dengan kadar HbA1c. Simpulan pada penelitian ini adalah kepatuhan mengkonsumsi obat antidiabetik dapat menurunkan kadar HbA1c pada pasien diabetes melitus tipe 2 .
\end{abstract}

Kata Kunci: Diabetes Melitus Tipe 2, Kepatuhan, Kadar HbA1c

PENDAHULUAN

Diabetes Melitus (DM) adalah suatu kelompok penyakit metabolik dengan karakteristik hiperglikemia yang terjadi karena kelainan sekresi insulin, kerja insulin atau kedua-duanya. Hiperglikemia merupakan suatu kondisi medik berupa peningkatan kadar glukosa dalam darah melebihi batas normal dengan konsentrasi gula darah sewaktu $\geq 200 \mathrm{mg} / \mathrm{dl}$ atau gula darah puasa $\geq 126 \quad \mathrm{mg} / \mathrm{dl}$. Hiperglikemia menahun dan deregulasi metabolik pada DM berhubungan dengan kerusakan jangka panjang, disfungsi atau kegagalan beberapa organ tubuh, khususnya ginjal, mata, saraf dan pembuluh darah (Aru et al., 2014).

Menurut hasil dari International Diabetes Federation (IDF) Tahun 2017 prevalensi orang yang mengalami diabetes mellitus pada usia $20-79$ tahun di Australia mencapai 5,1\%, India 10,4\%, Brazil 8,1\%, Jerman 8,3\%, dan Jepang 5,7\%. Wilayah Asia Tenggara bertanggung jawab atas 159 juta kasus diabetes melitus di dunia pada tahun 2017, dimana Thailand 7,0\%, Filiphina

e-ISSN 2620-5890 
$7,1 \%$, Myanmar 4,6\%, Malaysia $16,7 \%$ dan Indonesia 6,3\%.

Prevalensi DM di Nusa Tenggara Barat (NTB) berdasarkan Riset Kesehatan Dasar Provinsi NTB Tahun 2018, mengalami peningkatan dari tahun sebelumnnya. Prevalensi penyakit DM di NTB, masuk ke dalam urutan ke-23 dari 35 provinsi dengan prevalensi penderita DM yaitu sekitar 1,5\%-2,0\%. Tingginya angka kejadian DM tipe 2 salah satunya di sebabkan oleh pengendalian penyakit DM yang masih kurang baik.

Salah satu faktor yang berperan dalam kegagalan pengontrolan glukosa darah pasien DM tipe 2 adalah ketidakpatuhan pasien terhadap pengobatan. Kepatuhan pengobatan adalah kesesuaian diri pasien terhadap anjuran atas medikasi yang telah diresepkan yang terkait dengan waktu, dosis, dan frekuensi. Tingkat kepatuhan ini diukur secara tidak langsung dengan metode yang menggunakan alat penilaian dari World Health Organisation (WHO) yaitu kuesioner Morisky Medication Adherence Scale (MMAS-8) (United States, 2013).

Parameter yang dapat digunakan dalam menilai pengendalian penyakit DM salah satunya adalah pengukuran kadar HbA1c. HbA1c merupakan hasil dari reaksi kimia antara glukosa yang ada di dalam darah dengan hemoglobin Jurnal Kedokteran

Vol. 05 No. 02 Juni 2020 sehingga HbA1c dapat bersirkulasi dalam tubuh selama masa hidup sel darah merah. Dengan demikian, HbA1c dapat menggambarkan konsentrasi glukosa darah rata-rata selama 2-3 bulan terakhir sehingga bisa dijadikan sebagai acuan dalam perencanaan pengontrolan glukosa darah (Ramadhan et al., 2015).

Menurut Kimberley $\mathrm{K}$, et al (2004) bahwa terdapat hubungan yang signifikan antara kepatuhan minum obat antidiabetik dengan kadar HbAlc. Hal ini merupakan bagian dari intervensi farmakologis yang mampu mengendalikan kadar glukosa darah pada pasien DM. Namun, hasil penelitian yang dilakukan oleh Adikusuma et al. (2017) menunjukkan hasil yang bertolak belakang dengan penelitian diatas yaitu tidak terdapat adanya hubungan yang signifikan antara kepatuhan mengonsumsi obat antidiabetik dengan kadar HbA1c.

Berdasarkan uraian tersebut dan perbedaan hasil penelitian di atas, maka peneliti ingin meneliti dengan tujuan untuk mengetahui hubungan kepatuhan mengonsumsi obat antidiabetik dengan kadar HbA1c pada pasien DM tipe 2 di Rumah Sakit Umum Daerah Provinsi Nusa Tenggara Barat.

\section{METODE PENELITIAN}

Jenis penelitian yang digunakan adalah penelitian analitik menggunakan p-ISSN 2460-9749 e-ISSN 2620-5890 
rancangan penelitian Cross sectional. Penelitian ini dilaksanakan di Rumah Sakit Umum Daerah Provinsi Nusa Tenggara Barat. Pengumpulan data penelitian dilaksanakan pada bulan Januari tahun 2020. Populasi pada penelitian ini adalah seluruh pasien DM tipe 2 yang berobat jalan di Poli Penyakit Dalam RSUD Provinsi Nusa Tenggara Barat Tahun 2019.

Sampel minimal yang didapatkan pada penelitian ini sebesar 83 responden, yang didapat dengan cara purposive sampling. Kriteria inklusi yang digunakan untuk mendapatkan sampel yaitu (1) Seluruh pasien DM tipe 2 yang berobat jalan di Poli Penyakit Dalam RSUD Provinsi NTB (2) Pasien DM tipe 2 yang sudah mendapatkan pengobatan minimal 3 bulan terakhir sebelum melakukan pengukuran kepatuhan dalam mengkonsumsi obat antidiabetik tanpamembedakan jenis obat yang dikonsumsi, (3) Pasien yang mengonsumsi Obat Hipoglikemik Oral (OHO), (4) Pasien yang telah melakukan pemeriksaan kadar HbA1c. Sedangkan kriteria ekslusinya adalah (1) Pasien dengan riwayat gagal ginjal, telah melakukan splenektomi dan pankreatomi, (2) Pasien DM tipe yang menggunakan insulin.

Cara pengumpulan data pada penelitian ini adalah data primer yang diperoleh dari hasil wawancara pasien Jurnal Kedokteran Vol. 05 No. 02 Juni 2020 menggunakan instrumen kuesioner MMAS-8 dan data sekunder yang diperoleh dari rekam medis di RSUD Provinsi NTB. Kuesioner ini dipakai untuk mengukur tingkat kepatuhan pasien dalam mengkonsumsi obat. Analisis data dilakukan menggunakan komputer melalui program SPSS for Windows $20^{\text {th }}$ Edition. Uji statistik yang digunakan dalam penelitian ini ada 2 . Pertama menggunakan analisis univariat, untuk distribusi frekuensi masing-masing variabel bebas dan terikat. Sedangkan yang kedua menggunakan analisis bivariat untuk melihat hubungan antara kedua variabel dengan uji statistik yang digunakan adalah chi-square. Kriteria pengujian terhadap hasil penelitian ini dinyatakan signifikan apabila nilai $\mathrm{p}$ kurang dari 0,05 (Dahlan, 2014).

\section{HASIL DAN PEMBAHASAN}

\section{Hasil Penelitian}

Tabel 1. Distribusi Responden

Berdasarkan Kelompok Usia dan Jenis Kelamin

\begin{tabular}{ccccc}
\hline Kelompok & \multicolumn{5}{c}{ Jenis Kelamin } \\
\cline { 2 - 5 } & $\begin{array}{c}\text { Laki } \\
\text {-laki }\end{array}$ & $\begin{array}{c}\text { Pere } \\
\text { mpua } \\
\text { n }\end{array}$ & $\mathrm{n}$ & $\%$ \\
\hline $\begin{array}{c}\text { 26-35 } \\
\text { Tahun }\end{array}$ & 1 & 0 & 1 & 1,2 \\
$36-45$ & 4 & 7 & 11 & 13,3 \\
Tahun & & & & \\
$46-55$ & 11 & 21 & 32 & 38,6 \\
Tahun & & & & \\
$56-65$ & 11 & 16 & 27 & 32,5 \\
& & \multicolumn{4}{c}{$\begin{array}{l}\text { p-ISSN 2460-9749 } \\
\end{array}$} & \multicolumn{4}{c}{ e-ISSN 2620-5890 }
\end{tabular}


Tahun

\begin{tabular}{ccccc}
$>65$ Tahun & 8 & 4 & 12 & 14,5 \\
\hline Total & 35 & 48 & 83 & 100 \\
\hline \multicolumn{4}{c}{ Berdasarkan } \\
\hline
\end{tabular}

tabel 1, dari 83 responden didapatkan bahwa karakteristik responden berdasarkan kelompok usia dan jenis kelamin sebagian besar berada pada kelompok usia 46-55 tahun yaitu sebanyak 32 orang $(38,6 \%)$ yang terdiri dari 11 orang laki-laki dan 21 orang perempuan. Sedangkan kelompok usia yang paling sedikit berada pada usia 26 - 35 tahun yaitu sebanyak 1 orang $(1,2 \%)$ yang hanya terdiri dari 1 orang laki-laki.

Tabel 2. Distribusi Responden

Berdasarkan Jenis Kelamin dan Tingkat Kepatuhan

\begin{tabular}{ccccc}
\hline Jenis & \multicolumn{4}{c}{ Tingkat Kepatuhan } \\
\cline { 2 - 5 } Kelamin & Patuh & $\begin{array}{l}\text { Tida } \\
\mathrm{k} \\
\end{array}$ & \multicolumn{1}{c}{ Patuh } & $\%$ \\
\hline Laki-Laki & 18 & 17 & 35 & 42,2 \\
$\begin{array}{c}\text { Perempua } \\
\mathrm{n}\end{array}$ & 21 & 27 & 48 & 57,8 \\
\hline Total & 39 & 44 & 83 & 100 \\
\hline
\end{tabular}

Berdasarkan data pada tabel 2 yang responden terbanyak adalah berjenis kelamin perempuan yaitu sebanyak 48 sampel $(57,8 \%)$ yang terdiri dari 21 orang yang patuh dan 27 orang yang tidak patuh.

Jurnal Kedokteran

Vol. 05 No. 02 Juni 2020
Pada tabel 3 menunjukkan dari 83 responden didapatkan distribusi responden berdasarkan kelompok usia dan tingkat kepatuhan sebagian besar berada pada kelompok usia 46-55 tahun yaitu sebanyak 32 orang $(38,6 \%)$ yang terdiri dari 18 orang yang patuh dan 14 orang tidak patuh. Sedangkan kelompok usia yang paling sedikit berada pada kelompok usia 26 - 35 tahun yaitu sebanyak 1 orang (1,2\%) yang hanya terdiri dari 1 orang yang patuh.

Tabel 3. Distribusi Responden

Berdasarkan Kelompok Usia dan Tingkat Kepatuhan

\begin{tabular}{ccccc}
\hline $\begin{array}{c}\text { Kelompok } \\
\text { Usia }\end{array}$ & \multicolumn{5}{c}{ Tingkat Kepatuhan } \\
\cline { 2 - 5 } & Patuh & $\begin{array}{c}\text { Tidak } \\
\text { Patuh }\end{array}$ & $\mathrm{n}$ & $\%$ \\
\hline $\begin{array}{c}\text { Tahun } \\
\text { Tay }\end{array}$ & 1 & 0 & 1 & 1,2 \\
$36-45$ & 4 & 7 & 11 & 13,3 \\
Tahun \\
$46-55$ \\
$\begin{array}{c}\text { Tahun } \\
56-65\end{array}$ & 18 & 14 & 32 & 38,6 \\
Tahun & 11 & 16 & 27 & 32,5 \\
$>65$ Tahun & 5 & 7 & 12 & 14,5 \\
\hline Total & 39 & 44 & 83 & 100 \\
\hline
\end{tabular}

Tabel 4. Distribusi Kelompok Usia Terhadap Rerata Kadar

HbA1c

\begin{tabular}{ccc}
\hline Kelompok & \multicolumn{2}{c}{ Kadar HbA1c } \\
\cline { 2 - 3 } & Terkontrol & $\begin{array}{c}\text { Tidak } \\
\text { Terkontrol }\end{array}$ \\
\hline 26-35 Tahun & - & - \\
36-45 Tahun & $6,1 \pm 0,26$ & $9,3 \pm 2,45$ \\
46-55 Tahun & $6,2 \pm 0,28$ & $8,9 \pm 2,03$ \\
\hline & \multicolumn{2}{c}{ p-ISSN 2460-9749 } \\
& e-ISSN 2620-5890
\end{tabular}




\begin{tabular}{ccc}
\hline $56-65$ Tahun & $6,1 \pm 0,25$ & $9,5 \pm 2,72$ \\
$>65$ Tahun & $6,2 \pm 0,12$ & $7,6 \pm 2,36$ \\
\hline
\end{tabular}

Berdasarkan data pada tabel di atas distribusi kelompok usia terhadap rerata kadar HbA1c didapatkan bahwa, rerata kadar HbAlc tidak terkontrol tertinggi terdapat pada kelompok usia 56-65 tahun dengan rerata 9,5. Sedangkan rerata kadar HbA1c terkontrol tertinggi terdapat pada kelompok usia 46-55 tahun dan >65 tahun dengan rerata 6,1 .

Tabel 5. Distribusi Jenis Kelamin Terhadap Rerata Kadar HbA1c

\begin{tabular}{ccc}
\hline Jenis & \multicolumn{2}{c}{ Rerata Kadar HbA1c } \\
\cline { 2 - 3 } Kelamin & Terkontrol & $\begin{array}{c}\text { Tidak } \\
\text { Terkontrol }\end{array}$ \\
\hline Laki-laki & $6,1 \pm 0,26$ & $9,1 \pm 2,47$ \\
Perempuan & $6,2 \pm 0,24$ & $9,2 \pm 2,52$
\end{tabular}

Dari hasil penelitian, berdasarkan karakteristik jenis kelamin terhadap rerata kadar HbA1c didapatkan bahwa jenis kelamin laki-laki memiliki rerata kadar HbA1c tidak terkontrol lebih tinggi dibandingkan dengan kadar HbA1c yang terkontrol, dimana nilai rerata kadar HbA1c tidak terkontrol 9,1. Begitu juga pada jenis kelamin perempuan rerata kadar HbA1c tidak terkontrol lebih tinggi dibandingkan dengan rerata kadar HbA1c terkontrol,

Jurnal Kedokteran

Vol. 05 No. 02 Juni 2020 dimana nilai rerata kadar $\mathrm{HbA1c}$ tidak terkontrol 9,2.

Tabel 6. Hubungan Kepatuhan Mengonsumsi Obat Antidiabetik Dengan Kadar

HbA1c.

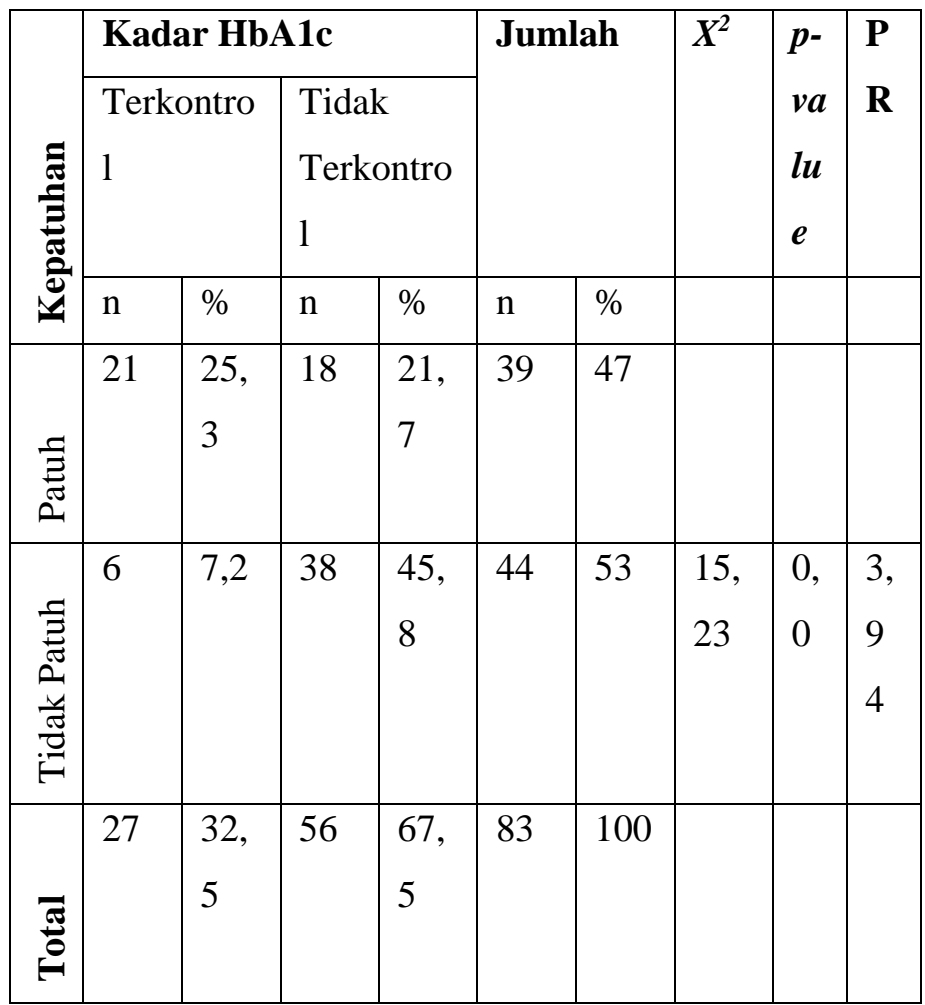

$\mathrm{PR}=\mathrm{A} /(\mathrm{A}+\mathrm{B}): \mathrm{C} /(\mathrm{C}+\mathrm{D})$

$=(29 / 39):(6 / 44)$

$=0,53: 0,13$

$=3,94$

Dari hasil analisis bivariat hubungan kepatuhan mengonsumsi obat antidiabetik dengan kadar HbAlc didapatkan bahwa responden yang patuh dalam mengosumsi obat dengan kadar 
HbA1c terkontrol sebanyak 21 responden $\quad(25,3 \%), \quad$ sedangkan responden yang patuh dalam mengonsumsi obat dengan kadar HbA1c tidak terkontrol sebanyak 18 responden $(21,7 \%)$. Responden yang tidak patuh dalam mengonsumsi obat dengan kadar HbA1c terkontrol didapatkan sebanyak 6 responden (7,2\%), sedangkan responden yang tidak patuh dengan kadar HbA1c tidak terkontrol sebanyak 38 responden $(45,8 \%)$.

Hasil uji Chi Square diperoleh nilai signifikan $0,000(p<0,05)$, terjadi penolakan terhadap $\mathrm{H}_{0}(p<0,05)$ dan penerimaan $\mathrm{H}_{1} \quad(p>0,05)$ yang berarti terdapat hubungan bermakna antara kepatuhan mengonsumsi obat antidiabetik dengan kadar HbA1c pada pasien DM tipe 2 di RSUD Provinsi NTB Tahun 2020.

Berdasarkan hasil perhitungan rasio prevalensi atau prevalence ratio (PR) diperoleh nilai 3,94 (PR>1), yang berarti responden yang tidak patuh berisiko 3,94 kali lebih besar untuk mengalami kadar HbA1c yang tidak terkontrol dibandingkan dengan yang patuh dalam mengonsumsi obat antidiabetik.

\section{Pembahasan}

Dari hasil pengumpulan data yang diperoleh peneliti, didapatkan sebagian besar kelompok usia terdapat pada Jurnal Kedokteran Vol. 05 No. 02 Juni 2020 rentang kelompok usia 44-55 tahun. Hasil penelitian ini sejalan dengan penelitian yang dilakukan Saptiningsih (2012) yang mendapatkan penderita DM terbanyak pada usia diatas 40 tahun. Hal ini disebabkan karena pada usia diatas 40 tahun, mulai terjadinya retensi insulin akan semakin meningkat disamping terdapat riwayat obesitas.

Secara fisiologis, tubuh manusia mengalami penurunan fungsi tubuh disaat memasuki usia 40 tahun. Seseorang dengan usia $>40$ tahun memiliki peningkatan risiko terhadap terjadinya DM dan intoleransi glukosa yang disebabkan oleh faktor degeneratif, khususnya kemampuan dari sel $B$ dalam mensekresikan insulin untuk mematabolisme glukosa (Saptiningsih, 2012).

Pada analisis hasil berdasarkan jenis kelamin, diketahui bahwa responden berjenis kelamin perempuan lebih banyak dibandingkan dengan responden yang berjenis kelamin lakilaki. Hal serupa juga didapatkan pada penelitian Trisnawati (2013) dimana responden perempuan lebih banyak dibandingkan laki-laki. Hal ini menunjukan bahwawanita lebih berisiko mengidap penyakit DM karena secara fisik wanita memiliki peluang peningkatan indeks masa tubuh yang lebih besar. Sindroma siklus bulanan (premenstrual syndrome), yang e-ISSN 2620-5890 
membuat distribusi lemak tubuh menjadi mudah terakumulasi akibat proses hormonal. Terjadinya penurunan hormon estrogen terutama saat masa menopause. Hormon estrogen dan progesteron memiliki kemampuan untuk meningkatkan respon insulin di dalam darah. Pada saat terjadinyamasa menopause, maka respon akan insulin menurun akibat hormon estrogen dan progesteron yang rendah (Taylor, 2010).

Pada analisis hasil berdasarkan distribusi kelompok usia dan tingkat kepatuhan, diketahui bahwa sebagian besar lebih banyak responden yang tidak patuh dibandingkan dengan responden yang patuh. Tingkat ketidakpatuhan yang tinggi terdapat pada kelompok usia 56-65 tahun. Hal ini dapat disebabkan oleh kelompok usia tersebut masih banyak responden yang belum mengerti akan pentingnya pengobatan pada pasien DM yang digunakan dalam waktu jangka panjang. Penelitian ini sejalan dengan hasil riset Nanda et al., 2018 yang menunjukkan bahwa lebih banyak responden yang tidak patuh dalam mengonsumsi obat dibandingkan dengan responden yang patuh. Selain itu, hal ini dapat juga disebabkan karena ketidaksengajaan pasien ataupun dilakukan secara sengaja dengan tidak meminum obat karena merasa penyakit yang diderita sudah membaik atau bertambah buruk. Untuk mengatasi hal Jurnal Kedokteran

Vol. 05 No. 02 Juni 2020 tersebut, peran farmasis sangat perlu ditingkatkan terkait penyakit dan penatalaksanaanya. Oleh karena itu, perlu adanya edukasi dan motivasi yang baik dari tenaga kesehatan atau dukungan dari keluarga agar dapat meningkatkan tingkat kepatuhan penggunaan obat dan kadar $\mathrm{HbA} 1 \mathrm{c}$ tetap terkontrol (Nanda et al, 2018).

Berdasarkan hasil penelitian mengenai karakteristik usia terhadap rerata kadar $\mathrm{HbAlc}$, didapatkan bahwa rerata kadar $\mathrm{HbAlc}$ tidak terkontrol tertinggi terdapat pada usia 56-65 tahun dengan rerata 9,5 sedangkan rerata kadar $\mathrm{HbA1c}$ terkontrol tertinggi terdapat pada usia 46-55 tahun dan >65 tahun dengan rerata 6,1 .

Sedangkan hasil penelitian mengenai karakteristik jenis kelamin terhadap rerata kadar $\mathrm{HbA1c}$ didapatkan baik itu pada jenis kelamin laki-laki maupun perempuan memiliki rerata kadar HbA1c yang tidak terkontrol lebih tinggi dibandingkan dengan rerata kadar HbA1c yang terkontrol. Hal ini mencermin bahwa jumlah responden yang memiliki kadar HbA1c yang tidak terkontrol lebih banyak dibandingkan dengan yang terkontol. Penelitian ini sejalan dengan penelitian Kusniyah (2017) dimana responden yang memiliki kadar HbA1c yang tidak terkontrol lebih banyak dibandingkan dengan kadar HbA1c yang terkontrol. Hal ini e-ISSN 2620-5890 
disebabkan karena HbA1C terkandung dalam eritrosit yang hidup sekitar 100120 hari, maka tingkat HbA1C yang buruk mencerminkan pengendalian metabolisme glukosa selama 3-4 bulan terakhir yang buruk. Tingkat HbA1C yang tidak terkontrol, mencerminkan ketidakpatuhan responden dalam menjalankan terapi antidiabetic.

Terapi antidiabetik merupakan terapi yang diberikan pada pasien yang mengidap penyakit DM untuk menilai manfaat pengobatan dan sebagai pegangan penyesuaian diet, latihan jasmani, dan obat-obatan untuk mencapai kadar glukosa darah yang normal, dan terhindar dari keadaan hiperglikemia ataupun hipoglikemia. Efektif atau tidaknya terapi diabetik yang diberikan bergantung pada hasil pemeriksaan HbA1C. Adapun terapi antidiabetik yang diberikan disamping insulin, terdapat pula obat hipoglikemik oral/OHO dengan pinsip kerja dari masing-masing obat yang berbeda, diantaranya sebagai pemicu sekresi insulin, penambah sensitivitas terhadap insulin, penghambat glukoneogenesis, dan penghambat absorpsi glukosa. Ketidakpatuhan dalam mengonsumsi obat antidiabetik akan menggaggu dari masing-masing efek obat sehingga menyebabkan kadar gula darah yang tidak terkontrol (Kusniyah et al., 2017).

Jurnal Kedokteran

Vol. 05 No. 02 Juni 2020
Kadar gula darah yang tidak terkontrol atau meningkat menyebabkan peningkatan proses ikatan gula darah dengan hemoglobin secara nonenzimatik melalui proses glikasi post translasi, hemoglobin yang terglikasi terlihat dalam beberapa asam amino $\mathrm{HbA}$ yang terdiri dari $\mathrm{HbA}_{1} \mathrm{a}, \mathrm{HbA}_{1} \mathrm{~b}$, dan $\mathrm{HbA}_{1} \mathrm{C}$. komponen yang terpenting dari glikasi hemoglobin tersebut dalam penyakit $\mathrm{DM}$ adalah $\mathrm{HbA}_{1} \mathrm{C}$, parameter ini digunakan sebagai patokan utama untuk pengendalian penyakit Diabetes Melitus karena $\quad \mathrm{HbA}_{1} \mathrm{C}$ dapat menggambarkan kadar gula darah dalam rentang waktu 1-3 bulan karena usia sel darah merah yang terikat oleh molekul glukosa adalah 120 hari. Semakin tinggi nilai $\mathrm{HbA}_{1} \mathrm{C}$ pada penderita DM maka semakin tinggi potensial terjadinya komplikasi pada pasien, kadar $\mathrm{HbA}_{1} \mathrm{C}$ dapat terkontrol dengan cara menjaga kestabilan glukosa dalam darah agar tetap normal (Amran et al., 2018).

Hasil penelitian menunjukkan bahwa terdapat hubungan yang signifikan antara kepatuhan mengonsumsi obat antidiabetik dengan kadar HbA1c pada pasien DM tipe 2 di RSUD Provinsi NTB dengan didapatkan hasil Uji Chi Square diperoleh tingkat signifikasi adalah 0,000 ( $<<0,05)$. Hal ini didukung oleh penelitian Kimberley (2004) dan Putri (2020) mengenai kepatuhan mengonsumsi obat dengan e-ISSN 2620-5890 
kadar HbA1c, yang menyatakan bahwa terdapat adanya hubungan antara kepatuhan mengonsumsi obat dengan kadar HbA1c. Hasil yang serupa juga ditunjukkan oleh penelitian Cahyono Widodo (2016) bahwa pada pasien DM Tipe 2 yang melakukan aktifitas fisik yang baik dengan tingkat kepatuhan mengonsumsi obat antidiabetik yang berkategori tinggi memiliki hubungan yang bermakna dengan kadar gula darah terkontrol.

Pada penelitian ini menggunakan hasil perhitungan prevalence ratio (PR) yang dimana PR digunakan pada penelitan Cross Sectional yang merupakan penelitian yang menggunakan data prevalensi. Dari hasil perhitungan PR diperoleh nilai 3,94 $(\mathrm{PR}>1)$, yang artinya responden yang tidak patuh memiliki risiko 3,94 kali lipat lebih besar mengalami kadar HbA1c yang tidak terkontrol dibanding responden yang patuh dalam mengonsumsi obat antidiabetik. Hal ini menyatakan bahwa terdapat hubungan kepatuhan mengonsumsi obat antidiabetik dengan kadar HbA1c pada pasien DM tipe 2.

Beberapa kelemahan pada penelitian ini (1) Desain penelitian cross sectional yang bersifat analitik yaitu pengambilan data risiko dan efek dilakukan pada saat yang bersamaan dan merupakan metode penelitian yang Jurnal Kedokteran

Vol. 05 No. 02 Juni 2020 sangat lemah. (2) Peneliti tidak dapat menghindari bias selama melakukan penelitian yaitu tingkat kejujuran responden pada saat menjawab kuesioner dan tingkat pendidikan responden yang berbeda sehingga pemahaman dalam menjawab kuesioner juga berbeda. (3) Keterbatasan waktu, tenaga, dan materi maka perlu dilakukan penelitian lebih lanjut mengenai keterkaitan konsumsi Obat Antidiabetik terhadap pengendalian kadar glukosa darah dengan metabolit lainnya pada Pasien DM tipe 2 di Rumah Sakit Umum Daerah Provinsi NTB.

\section{KESIMPULAN}

Berdasarkan hasil dan pembahasan mengenai Hubungan Kepatuhan Mengonsumi Obat Antidiabetik dengan Kadar HbA1c Pada Pasien DM Tipe 2 di Rumah Sakit Umum Daerah Provinsi NTB Tahun 2019, dapat disimpulkan bahwa karakteristik responden terbanyak berdasarkan jenis kelamin adalah perempuan dan usia terbanyak didapatkan pada kelompok usia 46 - 55 tahun. Sedangkan berdasarkan tingkat kepatuhan dan rerata kadar HbA1c didapatkan lebih banyak responden yang tidak patuh disertai rerata kadar HbAlc tidak terkontrol.

Dan berdasarkan hasil analisis didapatkan nilai $p$-value 0,000 yang p-ISSN 2460-9749 e-ISSN 2620-5890 
menyatakan bahwa terdapat adanya

hubungan yang signifikan antara

kepatuhan mengonsumsi obat

antidiabetik dengan kadar HbA1c pada

pasien DM tipe 2 di Rumah Sakit

Umum Daerah Provinsi NTB Tahun 2019.

\section{DAFTAR PUSTAKA}

Aru, W.S., Setiati, S., Alwi, I., Setiyohadi, B., \& Syam, A.F., 2014. Buku Ajar Ilmu Penyakit Dalam Jilid I Edisi VI. Jakarta: Ilmu Penyakit Dalam Fakultas Kedokteran Universitas Indonesia.

Amran, P., dan Rahman., 2018. Gambaran Hasil Pemeriksaan HbA1c Pada Penderita Diabetes Melitus Tipe 2 Di RSUD Labuang Baji Makassar, Volume 9: November, 2018.

Cahyono Widodo, Didik Tamtomo, Ari Natalia Prabandari. 2016. Hubungan Aktifitas Fisik, Kepatuhan Mengkonsumsi Obat Anti Diabetik dengan Kadar Gula Darah Pasien Diabetes Mellitus di Fasyankes Primer Klaten. JSK. Volume 2 Nomor 2 Desember 2016. Hal. 63-9

Dahlan, M.S., 2014. Statistik untuk Kedokteran dan Kesehatan: Deskriptif, Bivariat, dan Multivariat (Seri 1 Edisi 6). Jakarta: Epidemiologi Indonesia.

International Diabetes Federation (IDF). 2017. Diabetes Atlas, International Diabetic Federation.

Kimberley Krapek et al., 2004. Medication adherence and associated hemoglobin A1c in type 2 diabetes. Annals of Pharmacotherapy.

Jurnal Kedokteran

Vol. 05 No. 02 Juni 2020
Kusniyah Y, Nursiswati, Rahayu U. Hubungan Tingkat Self Care dengan Tingkat Hbalc pada Klien Diabetes Melitus Tipe 2 di Poliklinik Endokrin RSUP Dr. Hasan Sadikin Bandung; 2017: 11 .

Nanda, O.D., Wiryanto, B., Triyono, E.R., 2018. Hubungan kepatuhan minum obat antidiabetik dengan regulasi kadar gula darah pada pasien perempuan diabetes melitus, Volume 2: Nomor 4.

Ramadhan R., Marissa N., 2015, Karakteristik Penderita Diabetes Melitus Tipe 2 Berdasarkan Kadar HbA1c, Puskesmas Jayabaru Kota Banda Aceh, Volume 2:49-56 November, 2015 Number 2.

Riset Kesehatan Dasar (Riskesdas) 2018. Badan Penelitian Pengembangan Kesehatan Kementerian Kesehatan RI 2018. Jakarta: Riskesdas.

Saptiningsih, Monica. 2012. Determinan Infeksi Saluran Kemih Pasien Diabetes Mellitus Perempuan di RSB Bandung. Tesis. Fakultas Ilmu

Keperawatan.Program Magister Ilmu Keperawatan. Universitas Indonesia, Jakarta.

Taylor, C., Lilis., Lemme, P., \& Lynn, P. 2010. Fundamental of Nursing The Art and Science of Nursing Care $7^{\text {th }}$. Philadelpia : Lippincott.

United States. Centers for Disease Control and Prevention. 2013. Medication Adherence [online]. CDC's Noon Conference. Source: http://www.cdc.gov/primaryca re/materials/medication/docs/ medicationadherence01ccd.pdf.

Putri, Yunisa Arini. 2020. Korelasi Tingkat Kepatuhan Minum Obat Antidiabetik Oral p-ISSN 2460-9749 e-ISSN 2620-5890 
Terhadap Kadar HbA1c Pada Pasien Diabetes Melitus Tipe 2 Di Puskesmas Kedaton Bandar Lampung. Skripsi. Bandar Lampung 